\title{
THANKS TO REVIEWERS OF VOLUME 1
}

We rely on the generosity of our reviewers to contribute their time and expertise in order to improve the academic rigour of Journal of Social Inclusion articles. JoSI acknowledges the hard work of the following people who thoughtfully and comprehensively reviewed manuscripts for Volume 1 in 2010. We are very grateful for your support.

\begin{tabular}{|c|c|}
\hline $\begin{array}{l}\text { Lucinda Aberdeen } \\
\text { University of the Sunshine Coast, Queensland, } \\
\text { Australia } \\
\text { Nicole Asquith } \\
\text { University of Tasmania, Australia } \\
\text { Harriot Beazley } \\
\text { University of Queensland, Australia } \\
\text { Lyn Bender } \\
\text { Psychologist/Consultant, Melbourne, Australia } \\
\text { Judith Bessant } \\
\text { RMIT University, Melbourne, Australia } \\
\text { Tanmoy Bhattacharya } \\
\text { Indian Institute of Technology, Kharagpur, India } \\
\text { Christine Bigby } \\
\text { La Trobe University, Victoria, Australia } \\
\text { Michael Bleasdale } \\
\text { People with Disability Australia Ltd, NSW, Australia } \\
\text { Natalie Bolzan } \\
\text { University of Western Sydney, NSW, Australia } \\
\text { Grant Cairncross } \\
\text { Southern Cross University, NSW, Australia } \\
\text { Lesley Chenoweth } \\
\text { Griffith University, Queensland, Australia } \\
\text { Rhonda Craven } \\
\text { University of Western Sydney, NSW, Australia } \\
\text { Leanne Dowse } \\
\text { University of NSW, Australia } \\
\text { Jan Edwards } \\
\text { University of South Australia, Australia } \\
\text { Robyn Eversole } \\
\text { University of Tasmania, Australia } \\
\text { Simone Fullagar } \\
\text { Griffith University, Queensland, Australia } \\
\text { Rachel Fyson } \\
\text { University of Nottingham, UK } \\
\text { Susan Gabel } \\
\text { Auckland Disability Law Services, NZ } \\
\text { Manchester Metropolitan University, UK } \\
\text { Fran Gale } \\
\text { University of Western Sydney, NSW, Australia } \\
\text { Gerard Goggin } \\
\text { University of Sydney, NSW, Australia } \\
\text { Macquarie University, NSW, Australia } \\
\text { Andrea Hollomotz } \\
\text { Manam }\end{array}$ & 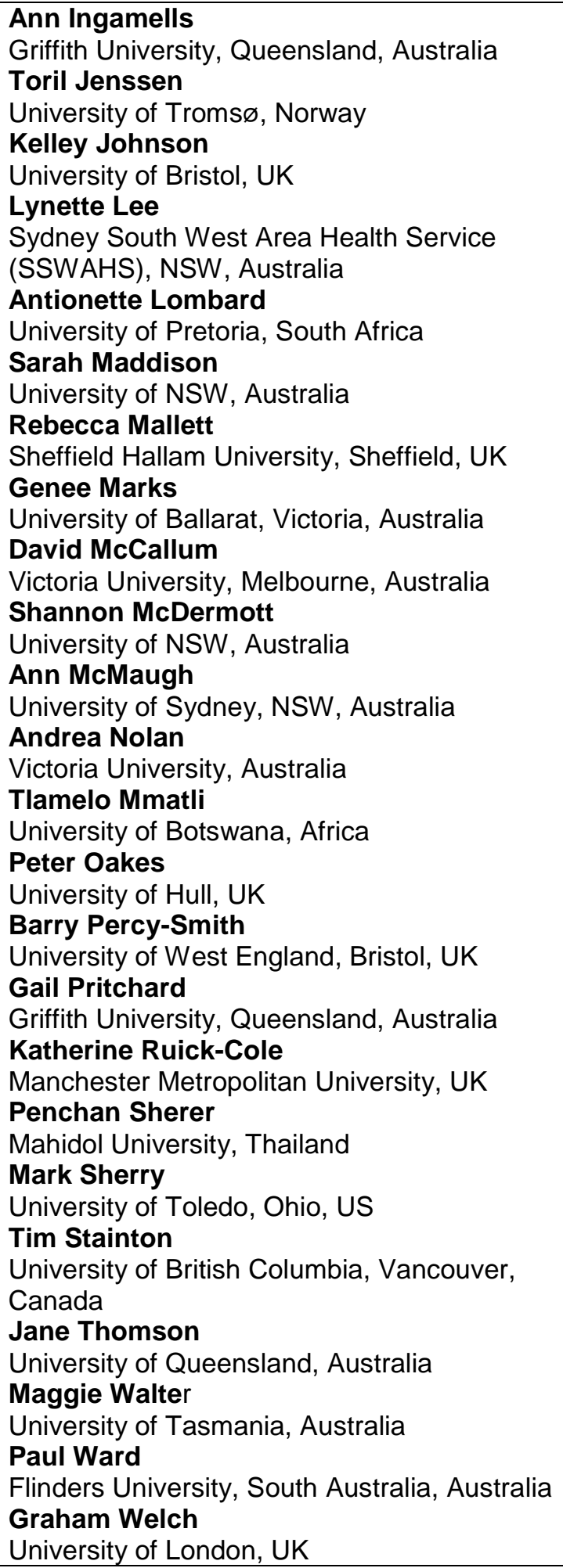 \\
\hline
\end{tabular}

